\title{
Armutta fidan kalitesi üzerine anaç ve çeşitlerin etkisi
}

\author{
Sevgi SERTTAȘ ${ }^{\circledR 1}$, Ahmet ÖZTÜRK ${ }^{\circledR 1}$ \\ 10ndokuz Mayıs Üniversitesi Ziraat Fakültesi Bahçe Bitkileri Bölümü, Atakum, Samsun
}

Alınış tarihi: 20 Nisan 2020, Kabul tarihi: 15 Haziran 2020

Sorumlu yazar: Ahmet ÖZTÜRK, e-posta: ozturka@omu.edu.tr

\section{Öz}

Bu çalışma, bazı armut klon anaçlarının üzerine aşılı armut çeşitlerinin fidan kalitesi üzerine etkisini belirlemek amacıyla 2018-2019 yılları arasında yürütülmüștür. Çalıșmada, 'Deveci', 'Williams', 'Santa Maria' ve 'Abate Fetel' armut çeşitleri dilciksiz aşı yöntemiyle Fox9, Fox11, OHxF87 ve OHxF333 armut klon anaçları üzerine aşılanmıştır. Araştırmada fidan kalitesini belirlemek amacıyla I. sınıf fidan oranı (\%), pazarlanabilir fidan oranı (\%), Dickson Kalite İndeksi ve Meyve Fidanı Kalite İndeksi incelenmiștir. Araștırmada incelenen tüm özellikler üzerine anaç ve çeşitlerin istatistiksel olarak önemli etkisinin olduğu saptanmış ve I. Sınıf fidan oranının \%78.7, pazarlanabilir fidan oranının \%98.5 olduğu belirlenmiştir. En yüksek I. sınıf fidan oranı Fox11 anacı üzerine aşılı 'Deveci' çeşidinde saptanmıştır. Pazarlanabilir fidan oranı anaçlar bakımından \%97.3-100.0; çeşitler arasında \%96.0-100.0 arasında değişim göstermiştir. Çeşitler bakımından en yüksek pazarlanabilir fidan oranı 'Deveci' ve 'Santa Maria', en düşük ise 'Abate Fetel' çeşidinde belirlenmiştir. Araştırmada fidan kalite indeksi olarak 'Dickson Kalite İndeksi' ve 'Meyve Fidanı Kalite İndeksi' çeşitler arasında sırasıyla 21.3-28.8 ve 18.7-60.7; anaçlar arasında 20.9-26.5 ve 22.1-66.0 arasında değișiklik göstermiștir. Modern meyveciliğin gereği olan dallı fidanların kalitesinin belirlenmesinde 'Dickson Kalite İndeksi'ne göre 'Meyve Fidanı Kalite İndeksi'nin kullanımının daha yararlı olacağı sonucuna varılmıştır. En yüksek kalitede fidanlar 'Deveci'/Fox9 kombinasyonunda belirlenmiştir. $\mathrm{Bu}$ çalışma sonucunda elde edilen fidanların kaliteli olduğu ve incelenen çeşitlerin armut klon anaçları üzerinde sürgün dönemde başarılı olarak yetiştirilebileceği kanısına varılmıştır.
Anahtar kelimeler: Armut, anaç, fidan kalitesi, kalite indeksi, pazarlanabilir fidan

\section{The influence of pear clonal rootstock and cultivars on nursery plant quality}

\section{Abstract}

This study was evaluated to the effects on nursery plant quality of pear clone rootstocks and cultivars during the 2018 and 2019 years. In this study, 'Deveci', 'Williams', 'Santa Maria' and 'Abate Fetel' pear cultivars were grafted in April on the Fox9, Fox11, OHxF87 and OHxF333 pear clone rootstocks with splice grafting method. In this study, first class nursery plant ratio (\%), marketable nursery plant ratio (\%),'Dickson Quality Index' and 'Fruit Sapling Quality Index' were evaluated as nursery plant quality. Rootstocks and cultivars had statistically significant effects on investigated all parameters and first class nursery plant ratio was determined as $78.7 \%$, marketable nursery plant ratio was determined as $98.5 \%$ in the study. The highest first class nursery plant ratio was found in the 'Deveci' cultivar grafted on Fox 11 rootstock. The marketable nursery plant ratio ranged from $97.3 \%$ to $100.0 \%$ in terms of rootstocks mean, and also $96.0-100.0 \%$ in terms of cultivar means. The highest marketable nursery plant ratio was observed from 'Deveci' and 'Williams' and the lowest in 'Abate Fetel' in terms of cultivars. In the study, the nursery plant quality as the Dickson Quality Index and the Fruit Sapling Quality Index were 21.3 - 28.8 and 18.7-60.7, respectively, in terms of the cultivars; they were 20.9-26.5 and 22.1-66.0, respectively, in terms of the rootstocks. It was concluded that the use of the 'Fruit 
Sapling Quality Index' would be more beneficial than the 'Dickson Quality Index' in determining the quality of branched saplings, which is a requirement of modern fruit growing. In this study, it was concluded that examined pear cultivars can be grown successfully on pear clone rootstocks. The highest quality nursey plant was observed from in 'Deveci'/Fox9 grafting combination. As a consequence of this study, we concluded that obtained nursery plants are good quality and the examined pear cultivars can be successfully grown on the pear clonal rootstock in the sprouting period.

Key words: Pear, rootstocks, nursery plant quality, quality index, marketable nursery plant

\section{Giriş}

Armut (Pyrus comminus L.) Rosales takımının, Rosaceae familyasının, Pyrus cinsi içerisine girmektedir. Dünyada yetiştiriciliği yapılan ve 22 türü bulunan Pyrus cinsinin içerisinde Pyrus communis L. ekonomik olarak yetiştiriciliği yapılan en önemli türdür (Bell ve ark., 1996; Hancock ve Lobos, 2008; da Silva ve ark., 2018). Armut, hem üretim alanı hem de üretim miktarı bakımından ılıman iklim meyve türleri içerisinde elma ve üzüm'den sonra 3. sırada yer alan önemli bir meyve türüdür. FAO verilerine göre yaklaşık 23.7 milyon ton olan 2018 yılı Dünya armut üretiminin 519.451 tonluk kısmını karşılayan Türkiye bu üretim değerleriyle Dünya armut üretiminde \% 2.1'lik paya sahiptir. Türkiye; Çin, A.B.D., İtalya ve Arjantin'den sonra en fazla armut üretimi yapan 5. ülke konumundadır. Ayrıca 1.381.923 ha olan Dünya armut üretim alanında Türkiye 26.389 ha'lık alan (\%1.9) ile yine 5. sirada yer almaktadır (FAOSTAT, 2020). Son ylllarda Dünya armut üretim alan ve miktarında azalma meydana gelmesine rağmen Türkiye armut üretim alan ve miktarında artış meydana gelmiștir. Çok farklı ekolojik ve coğrafik özelliklere sahip olan Türkiye'de armut yetiştiriciliği hemen hemen bütün bölgelerde yapılmaktadır (Özbek, 1978; Özçağıran ve ark., 2005). Türkiye çok fazla armut çeşit sayısına sahip olmasının yanında üretim miktarı ve alanı bakımından Dünya armut üretiminde ilk 5 ülke içerisinde yer almasına rağmen 19.3 tonluk hektara verim ile 19. sırada yer alarak armut üretiminde lider olan Çin, Arjantin, İtalya, A.B.D'nin oldukça gerisinde kalmaktadır. Ülkemizde verimli ve pazar değeri yüksek çeşitlerle ismine doğru kaliteli fidanların kullanımındaki eksiklikler, uygun anaç kullanımındaki yetersizlikler, üretimde kaliteli standart çeşitlerin kullanılmaması ve üretimde modern meyveciliğin gerekleri olan kültürel uygulamaların yeterince uygulanamaması, verim düşüklüğünün nedenleri arasında sayılabilir (Çelik ve Sakin 1991; Güleryüz, 1991). Yüksek getirisi dolayısıyla armut yetiştiriciliğine ilgi her geçen gün artmaktadır (Özçağıran ve ark., 2005; Swierczynski ve ark., 2014; Öztürk ve Öztürk, 2014). Artan bu ilgi de uygun çeşit/anaç kombinasyonunda üretilmiş ismine doğru, kaliteli ve bol miktarda fidan üretimini gerektirmektedir (Askari-Khorasgani ve ark., 2019).

Meyveciliğin karlı ve ekonomik olması ve daha da geliştirilebilmesi için, bahçe tesisinde kullanılacak fidanlar; ismine doğru, kaliteli, sağlıklı, hastalık ve zararlılardan ari, yeni ve pazar değeri yüksek çeşitler ile üretilmeli ve bu fidanların yeterli sayıda ve kısa bir süre içinde yetiştiricilere ulaştırılması gerekmektedir (Özongun ve ark., 2002; Jackson, 2003; Hancock ve Lobos, 2008; Saracoglu ve Cebe, 2018). Armut yetiştiriciliğinde genellikle çöğür yada klon anaçlar üzerine aşılanmış fidanlar kullanılmaktadır. Günümüz modern armut yetiştiriciliğinde kuvvetli büyüme ve gelişme gösteren çögür anaçları yerine bodur yada yarı bodur gelişme gösteren ayva ve armut klon anaçları kullanılmaktadır (Hartmann ve ark., 2011; Bolat ve İkinci, 2019; Hepaksoy, 2019). Bu anaçlardan ayva klon anaçlarına göre armut klon anaçları daha güçlü gelişme göstermekte, bu yüzden dikim mesafeleri daha geniş olmaktadır (Özçağıran ve ark., 2005; Sharma ve ark., 2010). Ayva anaçları üzerine armutlar aşılandığında ağaçların gelişme kuvvetlerinin kontrolünün (bodurluk) sağlanmasının yanında verimde erkencilik, meyve verim ve kalitesinde artış sağlanmasına rağmen bu anaçlarının kış soğuklarına, kireçli topraklarda kloroza ve ateş yanıklığına hassasiyet, toprağa iyi tutunamama ve zayıf aşı uyuşması gibi olumsuz yönleri dolayısıyla bunların yerine farklı anaç ıslah programlarında geliştirilen Pyrodwarf, OHxF, Farold, Fox ve BP serisi armut klon anaçları son yıllarda kullanılmaya başlanmıştır (Jackson, 2003; Hancock ve Lobos, 2008; Sharma ve ark., 2010; Dondini ve Sansavini, 2012). Anaçlar bitkilerinin kök sistemlerini oluştururlar ve üzerlerine aşlanan çeşitlerin uzun süre yaşama ve verim vermelerine etki ederler. Bunun yanında, armut yetiștiriciliğinde kullanılacak çeşitlerin seçimi kadar değişik iklim ve toprak koşullarına uyum, hastalık-zararlılara dayanım, gelişme kuvveti, verim ve kalite gibi birçok 
faktöre etki eden amaca uygun anaç seçilmesi meyve yetiştiriciliğinde son derece önemlidir (Bolat ve İkinci, 2019; Hepaksoy, 2019). Bu armut anaçlarının üzerlerine aşılanan çeşitlerin büyüme ve gelișme kuvvetleri üzerine etkilerinin incelenmesi ve bu durumun net bir şekilde ortaya konulması armut yetiştiriciliği için önemlidir. Ayrıca bu anaçlar üzerine aşlanan çeşitlerin fidan gelişme performansları ve fidan kaliteleri ile aşı uyuşma durumlarının (Cetinbaș ve ark., 2018; Rahman ve ark., 2017; Zenginbal ve Bostan, 2019) ortaya konulması bu fidanlarla yetiștiricilik yapacak olan armut üreticisi açısından oldukça önemlidir (Hepaksoy, 2019).

$\mathrm{Bu}$ araștırma ile ülkemizde son yıllarda yeni kullanılmaya başlayan bazı armut klon anaçlarının üzerlerine aşılanan armut çeşitlerinin fidan kalitesine etkisi ortaya konulmaya çalışılmıştır.

\section{Materyal ve Yöntem}

Bu çalışma, 2018-2019 yıllarında Ondokuz Mayıs Üniversitesi Ziraat Fakültesi Bahçe Bitkileri Bölümü Araştırma ve Uygulama Arazisine ait fidanlık parselinde ve laboratuvarlarında yürütülmüștür. Çalışmada anaç olarak doku kültürü yöntemiyle fidan üretimi yapan özel bir firmadan temin edilmiş olan $\mathrm{OH} x \mathrm{~F} 333, \mathrm{OH} x \mathrm{~F} 87$, FOX9 ve FOX11 armut klon anaçları ile kalem materyali olarak da ülkemiz armut yetiştiriciliğinde önemli paya sahip olan 'Deveci', 'Williams', 'Santa Maria' ve 'Abate Fetel' armut çeşitleri kullanılmıştır. Araştırmada kullanılan klon anaçlar deneme arazisine Nisan 2017 ve 2018'de 1,5 $\mathrm{m} \times 0,25 \mathrm{~m}$ sıra arası ve sıra üzeri mesafelerle dikilmiştir.

Deneme llıman iklime sahip olan Samsun ilinde yürütülmüştür. Samsun ilinde uzun yllar iklim verileri incelendiğinde ilde ortalama en yüksek sıcaklığın $27.0^{\circ} \mathrm{C}$; ortalama en düşük sıcaklığın $3.8^{\circ} \mathrm{C}$; yıllık ortalama sıcaklığın $14.5{ }^{\circ} \mathrm{C}$; yıllık ortalama yağışın 716 mm olduğu ve bu yağışların daha çok sonbahar ve kış aylarında olduğu görülmektedir (MGM, 2019).

Așlamada kullanılacak kalemler araștırma ve uygulama bahçesine daha önceki yıllarda dikilen damızlık ağaçlardan kış dinlenme döneminde temin edilmiş olup aşılama zamanına kadar polietilen poşetler içerisinde soğuk hava deposunda $+4{ }^{\circ} \mathrm{C}^{\prime} \mathrm{de}$ muhafaza edilmiştir (Hartmann ve ark., 2011; Öztürk ve ark., 2011). Denemede 1 yaşlı anaçlar üzerine çeşitler dilciksiz aşı yöntemiyle (Yılmaz, 1994; Lewis ve McE Alexander, 2008) sıcaklığın aşılama için uygun olduğu Nisan ayında aşılanmıştır. Yabancı ot kontrolü sıralar arasına siyah agroteks malç materyali çekilerek yapılmıştır. Deneme arazinde sulama damla sulama yöntemiyle yapılmış olup, gübreleme ve yabancı ot kontrolü gibi kültürel uygulamalar düzenli olarak yapılmıştır.

Araştırmada büyüme mevsimi sonunda yapılan çap ve boy ölçümleri dikkate alınarak fidan kalite sınıfları aşağıda belirtildiği şekilde belirlenmiştir.

\section{Sınıf Fidan Oranı (\%): Anaç/çeşit} kombinasyonuna göre her tekerrürdeki aşılı tüm bitkilerin fidan çap ve boyları belirlendikten sonra Hepaksoy (2008)'unda bildirdiği TSE (Anonim, 1997) ve Karamürsel (2008)'in bildirdiği standartlar dikkate alınarak fidan sinıfları 1. sinıf, 2. sinıf ve ıskarta olarak belirlenmiş olup, 1 yaşlı fidanlarda 20 mm çap ve $135 \mathrm{~cm}$ boya sahip olan fidanlar 1 . sınıf fidan olarak belirlenmiştir.

Pazarlanabilir Fidan Oranı (\%): Anaç/çeşit kombinasyonuna göre her tekerrürdeki aşılı tüm bitkilerin fidan çap ve boyları belirlendikten sonra Hepaksoy (2008) ve Karamürsel (2008)'in bildirdiği standartlar dikkate alınarak sınıfları 1. ve 2. sınıf olan fidanların toplamı olarak belirlenmiștir.

Dickson Kalite İndeksi (DKI): Araştırmada incelenen çeşit/anaç kombinasyonlarına göre fidan kalitesini belirlemek amacıyla orman ağaçlarının fidanları için Dickson ve ark. (1960) tarafından geliştirilmiş olan formülün kullanımı meyve fidanlarında denenmiştir. Dickson kalite indeksi 1' e yakın ve daha yüksek bulunduğu durumlarda fidanın kaliteli olduğu bildirilmiştir (Aslan, 1986). Dickson Kalite İndeksi aşağıda verilen formüle göre hesaplanmıștır;

$$
\text { Dickson Kalite Indeksi (DKI) }=\frac{\text { Fidan Kuru Ağırlı̆ı }(\mathrm{g})}{\frac{\text { Fidan Boyu }(\mathrm{cm})}{\text { Kök Boğazı çapı (mm) }}+\frac{\text { Gövde Kuru Ağırlığı (g) }}{\text { Kōk Kuru Ağırlığı (g) }}}
$$

Meyve Fidan Kalite İndeksi (MFKi): İyi şekilde gelişmiş çok sayıda yan dalın bulunmasının istendiği günümüz meyve yetiştiriciliğinde kullanılacak fidanlarda buna uygun bir sinıflandırma sisteminin de geliştirilmesi gerekliliğini vurgulayan Şahin (2014) bu düşünceyle Dickson Kalite İndeksine yan dal sayısı ve uzunluğunun da çarpan olarak eklendiği bir formül geliştirmiştir. Araştırmada incelenen çeşit/anaç kombinasyonlarına göre meyve fidan kalitesini belirlemek amacıyla Şahin (2014) tarafından geliştirilen aşă̆ıda belirtilen formül kullanılmıştır.

MFKI $=$ DKI $\mathrm{x}$ DS $\mathrm{x}[1+$ YDU $(\mathrm{m})]$ 
MFKI= Meyve Fidanı Kalite İndeksi

DKI= Dickson Kalite İndeksi

DS= 1 [(ana sürgün de dal olarak hesaba katılmıștır) + yan dal sayısı]

YDU= Yan dal uzunluğu (m)

Deneme tesadüf parselleri deneme desenine göre 3 tekerrürlü ve her tekerrürde 15 fidan (aşı) olacak şekilde 4 anaç ve 4 çeşit ile kurulmuştur. Araştırmada \% olarak elde edilen verilere $\operatorname{arc}-\sin \sqrt{\mathrm{x}}$ transformasyonu yapılmış olup tablolarda orijinal veriler kullanılmıştır. Elde edilen veriler IBM SPSS 21.0 istatistik paket programında analiz edilmiştir. Elde edilen ortalamalar arasındaki farklılıklar 'Duncan Çoklu Karşılaştırma Testi' ile \%5 (p > 0.05) olasılık sınırına göre belirlenmiştir. Araştırma verileri çizelge ve şekillerde 2 yılın ortalaması olarak sunulmuştur.

\section{Bulgular ve Tartışma}

\section{Sınıf fidan oranı}

Farklı anaçlar üzerine aşılı standart bazı armut çeşitlerinin I. sınıf fidan oranı üzerine anaçların ve çeşitlerin istatistiksel olarak önemli etkisinin olduğu belirlenmiştir. Araştırmada armut çeşitleri Fox11, Fox9 ve OHxF87 anaçları üzerine aşılandığında 1. sınıf fidan oranının en yüksek (sırasıyla \%88.1, \%81.0 ve \%80.8), OHxF333 üzerine aşılandığında ise en düşük (\%64.9) olduğu saptanmıştır. Çeşitler bakımından en yüksek 1. sınıf fidan oranı 'Deveci' ve 'Williams' çeşitlerinde (\%89.9 ve \%88.7), en düşük ise 'Abate Fetel' çeşidinde belirlenmiștir (\%59.5) (Çizelge 1, Şekil 1).

Araștırma sonucunda 'Deveci', Williams' ve 'Abate Fetel' armut çeșitlerinde 1. sınıf fidan oranı üzerine anaçların istatistiksel olarak önemli etkisinin olmadığı, 'Santa Maria' çeşidinde ise istatistiksel olarak önemli etkisinin olduğu saptanmıştır. 'Santa Maria' çeşidi Fox9 üzerine aşılandığında 1. sınıf fidan oranının en yüksek (\%90.3), OHxF333 üzerine aşılandığında ise en düşük (\%55.1) olduğu belirlenmiştir (Çizelge 1, Şekil 1).

Araştırma sonucunda çap ve boy ölçümleri göz önünde tutulduğunda Hepaksoy (2008)'in sınıflamasına göre elde edilen fidanların \%78.7'sinin 1. sınıf, \%19.8'nin 2. sınıf ve \%1.5'nin iskarta olduğu belirlenmiştir. Araştırmada 1. sınıf fidan oranı üzerine hem anaçların hem de çeşitlerin etkisinin olduğu tespit edilmiştir. Karamürsel (2008), bazı elma çeşitlerinde farklı aşı metotlarının örtüaltı ve açıkta fidan yetiştiriciliğini incelediği çalışmada 1. sınıf fidan oranı üzerine yetiştirme ortamı, anaç, çeşidin ve aşı yönteminin etkisinin önemli olduğunu vurgulamıştır. Araştırmada 1. sınıf fidan oranının, yetiştirme ortamı bakımından sera ortamında \%94.4, dış ortamda \%66.7; anaçlar bakımından 1. sınıf fidan oranı; M9 anacinda \% 72.7, MM 106 anacında \% 88.3; çeşitler bakımından Mondial Gala \% 88.1, Braeburn \% 86.1 ve Red Chief çeşidinde \% 67.5; aşı yöntemi bakımından dilcikli aşıda \%82.1, yongalı aşıda \%78.9 olduğu belirlenmiştir.

Çizelge 1. Standart bazı armut çeşitlerinin I. sınıf fidan oranı (\%) ve pazarlanabilir fidan oranı (\%) üzerine farklı armut klon anaçlarının etkisi

\begin{tabular}{|c|c|c|c|c|c|}
\hline \multirow{3}{*}{ Anaçlar } & \multicolumn{4}{|c|}{ Çeşitler } & \multirow{3}{*}{ Anaç Ortalaması } \\
\hline & Deveci & Williams & Santa Maria & Abate Fetel & \\
\hline & \multicolumn{4}{|c|}{ 1.Sınıf Fidan Oranı (\%) } & \\
\hline Fox 9 & $93.9 \mathrm{~A}^{* * *}$ & $92.1 \mathrm{~A}$ & $90.3 \mathrm{~A}$ & $47.6 \mathrm{~A}$ & $81.0 \mathrm{a}^{*}$ \\
\hline Fox 11 & $97.4 \mathrm{~A}$ & $97.3 \mathrm{~A}$ & $83.0 \mathrm{AB}$ & $74.2 \mathrm{~A}$ & $88.1 \mathrm{a}$ \\
\hline OHxF 333 & $83.3 \mathrm{~A}$ & $72.9 \mathrm{~A}$ & $55.1 \mathrm{~B}$ & $42.1 \mathrm{~A}$ & $64.9 \mathrm{~b}$ \\
\hline OHxF 87 & $85.0 \mathrm{~A}$ & $85.8 \mathrm{~A}$ & $78.3 \mathrm{AB}$ & $73.9 \mathrm{~A}$ & $80.8 \mathrm{a}$ \\
\hline \multirow[t]{2}{*}{ Çeşit Ortalaması } & $89.9 \mathrm{a}^{* *}$ & 88.7 a & $76.7 \mathrm{~b}$ & $59.5 \mathrm{c}$ & \\
\hline & \multicolumn{4}{|c|}{ Pazarlanabilir Fidan Oranı (\%) } & \\
\hline Fox 9 & $100.0 \mathrm{~A}^{* * *}$ & $100.0 \mathrm{~A}$ & $100.0 \mathrm{~A}$ & $97.6 \mathrm{~A}$ & $99.4 a^{*}$ \\
\hline Fox 11 & $100.0 \mathrm{~A}$ & $100.0 \mathrm{~A}$ & $100.0 \mathrm{~A}$ & $100.0 \mathrm{~A}$ & $100.0 \mathrm{a}$ \\
\hline OHxF 333 & $100.0 \mathrm{~A}$ & $100.0 \mathrm{~A}$ & $100.0 \mathrm{~A}$ & $89.7 \mathrm{~A}$ & $97.4 \mathrm{a}$ \\
\hline OHxF 87 & $100.0 \mathrm{~A}$ & $100.0 \mathrm{~A}$ & $92.5 \mathrm{~B}$ & $96.7 \mathrm{~A}$ & 97.3 a \\
\hline Çeşit Ortalaması & $100.0 \mathrm{a}^{* *}$ & $100.0 \mathrm{a}$ & $98.1 \mathrm{ab}$ & $96.0 \mathrm{~b}$ & \\
\hline
\end{tabular}

*: Aynı sütunda aynı küçük harfle gösterilen anaç ortalamaları arasındaki farklılık istatistiksel olarak önemli değildir (p<0.05).

**: Aynı satırda aynı küçük harfle gösterilen çeşit ortalamaları arasındaki farklılık istatistiksel olarak önemli değildir (p<0.05).

***: Aynı sütunda aynı büyük harfle gösterilen anaç-çeşit ortalamaları arasındaki farklılık istatistiksel olarak önemli değildir (p<0.05). 


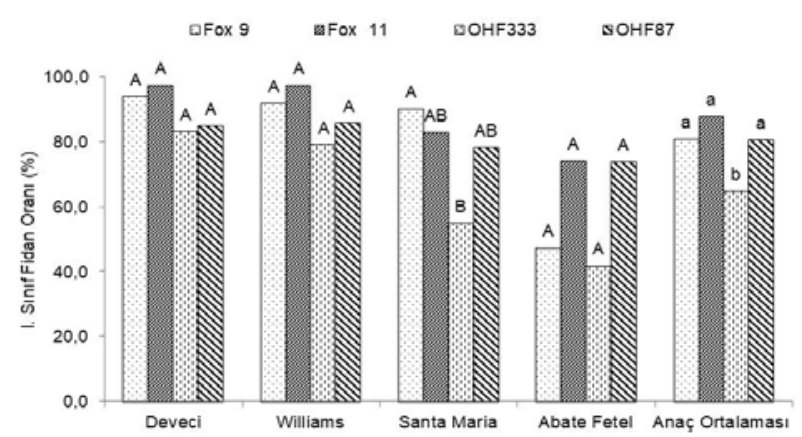

Şekil 1. Farklı armut çeșitlerinin I. sınıf fidan oranı (\%) üzerine anaçların etkisi (Aynı sütunda aynı harfle gösterilen anaç ortalamaları arasındaki farklılık istatistiksel olarak önemli değildir $(\mathrm{p}<0.05))$.

Örtüaltı ve açlk arazide tüplü armut fidanı üretiminde farklı anaç ve çeşitlere göre 1. yıl sonunda elde edilen fidanların sürgün çap ve boyları göz önüne alındığında TSE (1996) standartlarına göre 2. ve 3. sınıf oldukları bildirilmiştir (Zenginbal, 2016; Zenginbal ve Bostan, 2019). Araştırmamızdan elde edilen sonuçlar Karamürsel (2008)'in sonuçlarıyla benzerlik gösterirken Zenginbal ve Bostan (2019)'nın sonuçlarından oldukça yüksek olmuştur. Ortaya çıkan farklılığın anaç ve çeşit farklılığı ile yetiştirme ortamından kaynaklandığını söyleyebiliriz. Nitekim bitki fidan büyüme ve gelişmesinin çeşidin ve anacın genetik yapısına, ekolojiye ve yetiştirme ortamına bağlı olarak değiştiği bildirilmektedir (Rom ve Carlson, 1987; Jackson, 2003; Pektaş ve ark., 2009; Hartman ve ark., 2011; Rahman et al., 2017). Çalışmamızdan elde edilen fidanların büyük çoğunluğunun kalite sınıfı bakımından 1. ve 2. sınıf olduğu görülmektedir.

\section{Pazarlanabilir fidan oranı}

Araştırma sonucunda pazarlanabilir fidan oranı üzerine anaçların etkisi önemsiz olurken çeşitlerin istatistiksel olarak etkisinin önemli olduğu belirlenmiştir. Araştırmada pazarlanabilir fidan oranının anaç ortalamaları bakımından \%97.3$\% 100.0$; çeşit ortalamaları bakımından \%96.0$\%$ arasında değiștiği saptanmıştır. Pazarlanabilir fidan oranının 'Deveci' ve 'Williams' çeşitlerinde en yüksek (\%100.0 ve $\% 100.0$ ), 'Abate Fetel' çeşidinde ise en düşük olduğu belirlenmiştir (\%96.0). Araştırma sonucunda 'Deveci', 'Williams' ve 'Abate Fetel' çeşitlerinde anaçların pazarlanabilir fidan oranı üzerine istatistiksel olarak etkisinin olmadığı , 'Santa Maria' çeşidinde ise istatistiksel olarak etkisinin olduğu saptanmıştır. 'Santa Maria' çeşidi Fox9, Fox11 ve OHxF333 anaçları üzerine aşılandığında pazarlanabilir fidan oranı en yüksek (\%100.0) olurken, OHxF87 üzerine aşılandığında en düşük (\%92.5) olmuştur (Çizelge 1, Şekil 2).

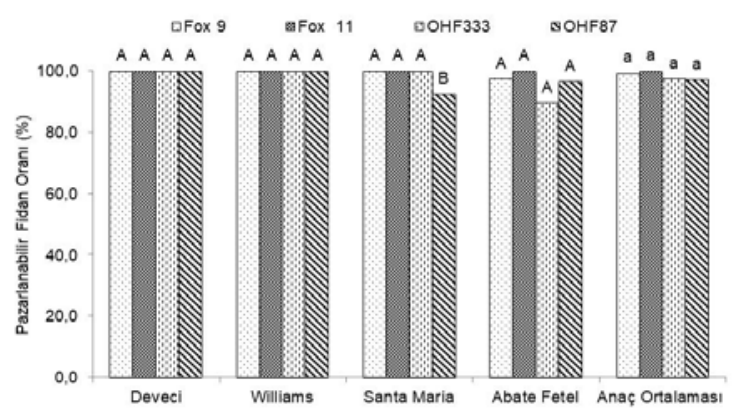

Şekil 2. Farklı armut çeşitlerinin pazarlanabilir fidan oranı (\%) üzerine anaçların etkisi (Aynı sütunda aynı harfle gösterilen anaç ortalamaları arasındaki farklılık istatistiksel olarak önemli değildir $(\mathrm{p}<0.05))$

Araştırmada pazarlanabilir fidan oranı üzerine armut çeşitlerinin önemli etkisinin olduğu, armut anaçlarının ise etkisinin önemli olmadığı tespit edilmiştir. Araştırmamızdan elde edilen fidanların \%98.5'nin pazarlanabilir kalitede olduğu saptanmıștır. $\mathrm{Bu}$ da yeter kalitede fidan elde edildiğini göstermektedir. Örtüaltı ve açlk arazide tüplü armut fidanı üretiminde farklı anaç ve çeşitlerin etkisini inceleyen Zenginbal (2016) 1. yll sonunda pazarlanabilir fidan oranı üzerine anaçların ve çeşitlerin önemli etkisinin olduğunu bildirmiştir. Araştırmada pazarlanabilir fidan oranı anaç ortalaması bakımından \%60.0-72.2; çeșitler ortalaması bakımından \%47.5-80.0 arasında değişim göstermiş ve elde edilen fidanların sürgün çap ve uzunlukları göz önüne alındığında TSE (1996) standartlarına göre 2 . ve 3 . sinıf oldukları vurgulanmıștır. Araştırmamızda elde ettiğimiz pazarlanabilir fidan oranı anaçlar bakımından farklılık oluşturmazken çeşitler bakımından farklılık oluşturmuștur. Anaçlar bakımından farklılığın olmamasını kullanılan armut klon anaçlarının büyüme güçlerinin benzer olmasına, çeşitlerin ise büyüme güçlerinin farklı olmasına bağlayabiliriz. Ayrıca araştırmamızda pazarlanabilir fidan oranı anaç ortalamaları bakımından \%97.3-100.0; çeşit ortalamaları bakımından \%96.0-100.0 arasında değişmiş ve önceki çalışmadan yüksek değerler elde edilmiştir. Ortaya çıkan farklılığın yetiştirme ortamı, anaç kuvveti ve ekolojiden kaynaklı olabileceğini düşünmekteyiz. Nitekim tüplü fidan üretiminde kullanılan ortam kök gelişmesini sınırlandırmakta ve 
bu durum da büyüme ve gelişmeye olumsuz yansımaktadır.

\section{Dicksen kalite indeksi (DKI) ve meyve fidanı kalite indeksi (MFKİ)}

Araștırmada farklı anaçlar üzerine așılı bazı armut çeşitlerinin fidan kalitesinin belirlenmesinde kullanılan Dickson Kalite İndeksi (DKI) üzerine anaçların ve çeşitlerin etkisinin önemli olduğu belirlenmiştir (Çizelge 2). Araştırmada DKİ anaç ortalamaları bakımından 20.9-26.5; çeşit ortalamaları bakımından ise 21.3-28.8 arasında değişim göstermiştir. Dickson Kalite İndeksinin Fox9 ve Fox11 anaçlarında en yüksek (26.5 ve 26.5), OHxF333 anacinda ise en düşük (20.9) olduğu saptanmıştır (Çizelge 2).

Çizelge 2. Standart bazı armut çeşitlerine ait fidanların Dickson Kalite İndeksi ve Meyve Fidanı Kalite İndeksi üzerine farklı armut klon anaçlarının etkisi

\begin{tabular}{|c|c|c|c|c|c|}
\hline \multirow{3}{*}{ Anaçlar } & \multicolumn{4}{|c|}{ Çeşitler } & \multirow{3}{*}{ Anaç Ortalamas } \\
\hline & Deveci & Williams & Santa Maria & Abate Fetel & \\
\hline & \multicolumn{4}{|c|}{ Dickson Kalite İndeksi } & \\
\hline Fox 9 & $31.4 \mathrm{~A}^{* * *}$ & $26.3 \mathrm{AB}$ & $24.9 \mathrm{~A}$ & $23.5 \mathrm{~A}$ & $26.5 \mathrm{a}^{*}$ \\
\hline Fox 11 & $23.3 \mathrm{AB}$ & $35.3 \mathrm{~A}$ & $25.8 \mathrm{~A}$ & $21.7 \mathrm{~A}$ & $26.5 \mathrm{a}$ \\
\hline OHxF 333 & $21.4 \mathrm{AB}$ & $24.1 \mathrm{~B}$ & $23.1 \mathrm{~A}$ & $15.1 \mathrm{~A}$ & $20.9 \mathrm{~b}$ \\
\hline OHxF 87 & $15.5 \mathrm{~B}$ & $29.7 \mathrm{AB}$ & $25.4 \mathrm{~A}$ & $24.8 \mathrm{~A}$ & $23.9 \mathrm{ab}$ \\
\hline Çeşit Ortalaması & $22.9 \mathrm{~b}^{* *}$ & $28.8 \mathrm{a}$ & $24.8 \mathrm{ab}$ & $21.3 \mathrm{~b}$ & \\
\hline \multicolumn{6}{|c|}{ Meyve Fidanı Kalite İndeksi } \\
\hline Fox 9 & $148.2 \mathrm{~A}^{* * *}$ & $28.0 \mathrm{AB}$ & $34.7 \mathrm{~A}$ & $53.1 \mathrm{~A}$ & $66.0 \mathrm{a}^{*}$ \\
\hline Fox 11 & $45.6 \mathrm{~B}$ & $85.8 \mathrm{~A}$ & $2.1 \mathrm{~A}$ & $45.1 \mathrm{~A}$ & $44.6 \mathrm{ab}$ \\
\hline OHxF 333 & $29.0 \mathrm{~B}$ & $79.4 \mathrm{~A}$ & $20.6 \mathrm{~A}$ & $35.2 \mathrm{~A}$ & $41.1 \mathrm{~b}$ \\
\hline OHxF 87 & $19.9 \mathrm{~B}$ & $2.0 \mathrm{~B}$ & $17.3 \mathrm{~A}$ & $49.2 \mathrm{~A}$ & $22.1 \mathrm{~b}$ \\
\hline Çeșit Ortalaması & $60.7 \mathrm{a}^{* *}$ & $48.8 \mathrm{a}$ & $18.7 \mathrm{~b}$ & $45.6 \mathrm{a}$ & \\
\hline
\end{tabular}

*: Aynı sütunda aynı küçük harfle gösterilen anaç ortalamaları arasındaki farklılık istatistiksel olarak önemli değildir (p<0.05).

**: Aynı satırda aynı küçük harfle gösterilen çeşit ortalamaları arasındaki farklılık istatistiksel olarak önemli değildir (p<0.05).

***: Aynı sütunda aynı büyük harfle gösterilen anaç-çeşit ortalamaları arasındaki farklılık istatistiksel olarak önemli değildir (p<0.05).

Dickson Kalite İndeksinin 'Williams' çeşidinde en yüksek (28.8), 'Abate Fetel' ve 'Deveci' çeşitlerinde ise en düșük (21.3 ve 22.9) olduğu belirlenmiștir. Araştırma sonucunda 'Santa Maria' ve 'Abate Fetel' çeşitlerinde anaçların DKİ üzerine istatistiksel olarak etkisinin olmadığı, 'Deveci' ve 'Williams' çeșitlerinde ise istatistiksel olarak önemli etkisinin olduğu belirlenmiştir. 'Deveci' çeşidi Fox9 üzerine aşllandığında DKİ'nin en yüksek (31.4), OHxF87 üzerine aşılandığında ise en düşük (15.5) olduğu tespit edilmiştir. 'Williams' çeşidi Fox11 üzerine aşılandığında DKİnin en yüksek (35.5), OHxF333 üzerine așılandığında ise en düșük (24.1) olduğu belirlenmiştir (Çizelge 2).

Orman ağaçlarının fidanlarında kaliteyi belirlemek için geliştirilen Dickson Kalite İndeksi üzerine araștırmamızda anaçların ve çeșitlerin önemli etkilerinin olduğu saptanmıştır. Orman ağaçları fidanlarında Dickson Kalite İndeksi değeri 1'e yakın ve daha yüksek bulunduğunda fidanlar kaliteli olarak değerlendirilmektedir. Araştırma sonuçlarımız incelendiğinde elde edilen değerlerin tümü 1 değerinin üstündedir ve elde edilen fidanlar DKİne göre kalitelidir. Malç (siyah ve şeffaf) ve promalin (perlan; $\mathrm{GA}_{4+7}+\mathrm{BA}$ ) uygulamalarının kuş kirazı (Prunus avium; Mazzard) anacı üzerine aşılı '0900 Ziraat' ve 'Sweet Heart' kiraz çeşitlerinin dallanması üzerine etkilerini inceleyen Şahin (2014) elde edilen fidanlarda Dickson Kalite İndeksi değerinin kontrol bitkilerinde 3.38-5.16 olduğunu bildirmiştir. Araştırmamızda elde edilen DKİ değerlerinin önceki çalışmaya göre yüksek olduğu görülmektedir. Araştırmamızda DKİnin önceki çalışmaya göre yüksek olmasını elde edilen sürgün uzunluğu ve sürgün kuru ağırlığının daha yüksek, kök kuru ağırlığının ise düşük (Serttaş, 2019) olmasına bağlayabiliriz. Sonuçta DKİnin hesaplanmasında kullanılan bitki kuru ağırlığının yüksek olması yanında sürgün boyunun ve sürgün kuru ağrılığının yüksek olması bu değerin daha yüksek olmasına 
neden olmaktadır. Ayrıca bu sonuçlar çeșide bağlı olarak kullanılan anaçlarında fidan gelişimine olumlu etki ettiklerini ortaya koymaktadır. Nitekim anaçların üzerine aşılanan çeşidin gelişimini etkilediği gibi çeşitlerinde üzerine aşılandığı anaçların gelişimini etkilediği vurgulanmaktadır (Rom ve Carlson, 1987; Dolkar ve ark., 2018; Bolat ve İkinci, 2019; Hepaksoy, 2019).

Farklı armut klon anaçlarının üzerine aşılı bazı armut çeșitlerinin Meyve Fidan Kalite İndeksi (MFKI) üzerine anaçların ve çeșitlerin istatistiksel olarak önemli etkisinin olduğu saptanmıștır. Araştırmada MFKI'nin anaç ortalamaları bakımından 22.1-66.0, çeşit ortalamaları bakımından 18.7-60.7 arasında değiştiği belirlenmiştir. MFKI'nin Fox9 anacında en yüksek (66.0), OHxF87 ve OHxF333 anaçlarında ise en düşük (22.1 ve 41.1) olduğu tespit edilmiştir. Meyve fidan kalite indeksinin 'Deveci', 'Williams' ve 'Abate Fetel' çeşitlerinde en yüksek (sırasıyla 60.7, 48.8 ve 45.6), 'Santa Maria' çeşidinde ise en düşük (18.7) olduğu belirlenmiştir. Araştırma sonucunda 'Santa Maria' ve 'Abate Fetel' çeşitlerinde anaçların MFKI üzerine istatistiksel olarak etkisinin olmadı̆̆ı, 'Deveci' ve 'Williams' çeşitlerinde ise istatistiksel olarak önemli etkisinin olduğu belirlenmiştir. 'Deveci' çeşidi Fox9 üzerine aşılandığında MFKİ'nin (148.2) diğer anaçlardan daha yüksek olduğu belirlenmiştir. 'Williams' çeşidi Fox11 ve $0 H x$ F333 üzerine aşllandığında MFKI'nin en yüksek (85.8 ve 79.4), $0 \mathrm{H} x \mathrm{~F} 87$ üzerine aşllandığında ise en düşük (2.0) olduğu belirlenmiştir (Çizelge 2).

Günümüz modern meyve yetiştiriciliğinde meyve verme yaşını erkene alan ve bu şekilde hem kaliteli hem de yüksek verimi garanti altına alan özellikle sık dikim meyve yetiştiriciliğinde dallanmış fidanların kullanımı zorunlu haline gelmiştir (Magyar ve ark., 2008). Orman ağaçlarının fidanlarında kaliteyi belirlemek için Dickson ve ark. (1960), tarafindan geliştirilmiş olan 'Dickson Kalite İndeksi' formülünde kaliteli meyve fidanında bulunması gereken yan dal ile ilgili bir özellik olmadığından meyve ağaçları için yetersiz kalmaktadır. Meyve ağaçları için yetersiz kalan bu formül Şahin (2014) tarafından meyve ağaçları için yan dal oluşumu da dikkate alınarak 'Meyve Fidanı Kalite İndeksi' geliștirilmiștir. Kök ve gövde ağırlığının özellikle orman ağacı fidanlarında ihmal edilmeyecek bir kalite göstergesi olduğu (Şimşek, 1987); kök ve gövde ağırlığı ve bunların birbirine oranı 'Dickson Kalite İndeksi' ile 'Meyve Fidanı Kalite İndeksinde' kullanılan parametrelerdir
(Şahin, 2014). Son yıllarda dallı fidan kullanımının yaygınlaşmaya başladığı modern meyveciliğin gereği; ağaçların erken meyveye yatması, birim alana verimin artırılması, budama, ilaçlama gibi kültürel işlemlerin rahat ve ekonomik bir şekilde yapılabilmesi, her yıl düzenli ve kaliteli ürün elde edilmesidir (Soylu ve ark., 2003). Meyve yetiştiriciliğinde kullanılan dallanmış fidanlar ilk yıllarda daha fazla çiçek tomurcuğu oluşturarak meyveye yatma yaşını erkene almakta ve iyi dallanmış bu fidanlar daha kaliteli meyveler vermektedir (Quinlan, 1978; Johann, 1983). Bu nedenle üretilen fidanlarda kaliteyi artıran iyi şekilde gelişmiş yan dalların sayısının da dikkate alındığı MFKİ fidan üretiminde kaliteyi belirlemede önemli bir ölçüttür.

Araştırmamızda MFKİ üzerine anaçların ve çeşitlerin istatistiksel olarak önemli etkisinin olduğu belirlenmiştir. Araştırmada Dickson Kalite İndeksi'nden farklı olarak yan dal sayısının yüksek olduğu anaç ve çeşitlerde MFKİ daha yüksek olmuştur (Serttaş, 2019). Nitekim Malç (siyah ve şeffaf) ve promalin (perlan; $\mathrm{GA}_{4+7}+\mathrm{BA}$ ) uygulamalarının kuş kirazı (Prunus avium; Mazzard) anacı üzerine aşılı '0900 Ziraat' ve 'Sweet Heart' kiraz çeşitlerinin dallanması üzerine etkilerini inceleyen Şahin (2014) kontrol uygulamalarına göre yan dal oluşumunun teşvik edildiği promalin+malç uygulamalarında MFKI'nin daha yüksek olduğunu bildirmiştir. Araştırmada herhangi bir uygulama yapılmayan kontrol uygulamasında MFKI'nin '0900 Ziraat' çeşidinde 4.56, 'Sweet Heart' çeşidinde 9.51 olduğu bildirilmiştir. Araștırmada belirlenen MFKI değerleri ile çalışmamızda elde edilen değerlerin oldukça farklı olduğu gözlemlenmiştir. Bu farklılığın tür farklılığı yanında kullanılan anaçların büyüme gücünden kaynaklandığını düşünmekteyiz. $\mathrm{Bu}$ durumu MFKI'nin hesaplanmasında kullanılan DKI'nde de belirtildiği üzere önceki çalışmaya göre çalışmada elde edilen bitki kuru ağırlığının, sürgün boyunun ve sürgün kuru ağrılığının yüksek, kök kuru ağırlı̆̆ının düşük (Serttaş, 2019) olmasına bağlayabiliriz. Yine DKİ'nden farklı olarak yan dal sayısı ve yan dal uzunluğu da MFKİ belirleme parametrelerinden olduğu için bu parametrelerin yüksek olduğu kombinasyonlarda MFKİ yüksek olmuştur. Ayrıca elde edilen bu sonuçlar çeşide bağlı olarak kullanılan anaçlarında fidan gelişimine olumlu etki ettiklerini ortaya koymuştur. 
Araştırmada farklı armut klon anaçları üzerine aşılanan armut çeșitlerinden elde edilen fidanların MFKI dikkate alındığında kaliteli oldukları ortaya konulmuştur.

\section{Sonuç ve Öneriler}

Çalışma sonucunda, araştırmada kullanılan armut klon anaçlarının üzerine aşılı çeşitlerin fidan kalitesi üzerine önemli etkisinin olduğu belirlenmiştir. Araștırmada 1. sınıf fidan oranı bakımından en yüksek sonuç Fox11 anacı üzerine aşılı 'Williams', en düşük sonuç ise OHxF333 anacı üzerine aşlı 'Abate Fetel' çeșidinden elde edilmiş olup elde edilen fidanların 1. ve 2. sinıf kalitede oldukları tespit edilmiştir. Çalışma sonucunda pazarlanabilir fidan oranının \%98.5 olduğu belirlenmiş olup, bu oran anaçlardan Fox11; çeşitlerden ise 'Deveci' ve 'Williams' çeşitlerinde en yüksek oluştur. En düşük pazarlanabilir fidan oranı 'Abate Fetel' çeşidi $\mathrm{OH} x \mathrm{~F} 333$ anacı üzerine aşılandığında elde edilmiştir. Araştırmada incelenen tüm çeşit/anaç kombinasyonlarından elde edilen fidanların 'Dickson Kalite İndeksi' ve 'Meyve Fidanı Kalite İndeksi'ne göre kaliteli olduğu belirlenmiştir. Ancak günümüz modern meyve yetiştiriciliğinde dalsız (kamçı) fidanlara göre kullanımı daha fazla yaygınlaşmaya başlayan iyi dallanmış, kaliteli ve çok sayıda yan dalın bulunduğu dallı fidanların kalite sınıfının belirlenmesinde 'Meyve Fidanı Kalite İndeksi'ne göre 'Dickson Kalite İndeksi'nin yetersiz kaldığı tespit edilmiştir. $\mathrm{Bu}$ çalışmadan elde edilen sonuçlar ışığında bundan sonraki yapılacak çalışmalarda fidan kalite kriteri olarak 'Dickson Kalite İndeksi' yerine 'Meyve Fidanı Kalite İndeksi'nin kullanımı yararlı olacaktır. I. sınıf fidan oranı, pazarlanabilir fidan oranı, Dickson kalite indeksi ve meyve fidanı kalite indeksi değerleri birlikte değerlendirildiğinde elde edilen fidanların kaliteli olduğu görülmüştür. Ayrıca Dünya armut üretiminde önemli bir yeri olan ülkemizin armut üretiminde olduğu gibi ticaretinde de ön sıralara yükselebilmesi için son yıllarda artmaya başlayan ismine doğru, kaliteli fidanlarla kurulmuş modern tarım tekniklerinin uygulandığı armut bahçesi sayısının daha da artırılması gerekmektedir. $\mathrm{Bu}$ araştırma ile armut yetiştiriciliğinde önemli olan kaliteli aşılı fidan talebinin sürgün dönemde başarılı bir şekilde yapılabileceğini söyleyebiliriz.

\section{Kaynaklar}

Anonim, (1997). Meyve ve asma çeşit/anaç damızlı̆̆ fidan üretim materyali ve fidanların sertifikasyonuna ait genel esaslar tebliği. Tebliğ No, 11, Resmi Gazete Sayı,22868, 5 Ocak 1997, 311, Ankara.

Askari-Khorasgania, O., Jafarpoura, M., Hadada M.M., \& Pessaraklib, M., (2019). Fruit yield and quality characteristics of "Shahmiveh" pear cultivar grafted on six rootstocks. Journal of Plant Nutrition 42(4), 323-332.

Aslan, S. (1986). Kazdağı göknarının fidanlık tekniği üzerine çalışmalar, Ormancılık Araştırma Enstitüsü Yayınları 157, 3-42.

Bell, R.L., Janick, J., \& Moore, J. N. (1996). Pears. Fruit Breeding Volume I, Tree and Tropical Fruits. John Willey and Sons Press, New York, 632 pp.

Bolat, İ., \& İkinci, A., (2019). Meyvecilikte anaç kullanımı. I. Uluslararası Harran Multidisipliner Çalışmalar Kongresi (8-10 Mart 2019, Şanlıurfa, Türkiye) Bildirileri, 278-283.

Çelik, M., \& Sakin, M., (1991). Ülkemizde meyve fidanı üretiminin bugünkü durumu, Türkiye 1. Fidancilık Sempozyumu (26-28 Ekim 1987, Tokat) Bildirileri, T.C. Tarım ve Köyişleri Bakanlığı, 169-180.

Çetinbaş, M., Butar, S., Sesli, Y., \& Yaman, B. (2018). Armut fidanı üretiminde farklı çeşit/anaç kombinasyonlarının bazı fidan özelliklerine etkisi üzerine araştırmalar. Gaziosmanpaşa Üniversitesi, Ziraat Fakültesi Dergisi, 35 (Ek Sayı), 8-12.

Da Silva G.J., Villa, F., Grimaldi F., da Silva P.S., \& Welter J.F.,2018. Pear (Pyrus spp.) Breeding (pp. 131-163). Advances in Plant Breeding Strategies, Fruits (Eds, Al-Khayri, J.M., Jain, S.M., Johnson D.M.), (pp 131163), Switzerland, Springer, pp. 990.

Dickson, A., Leaf, A.L., \& Hosner, J.F. (1960). Quality appraisal of white spruce and white pine seedling stock in nurseries. Forestry Chronicle 36(1), 10-13.

Dolkar, T., Mansoor, A., Agleema, B., Divya, S., Lobzang, S., \& Stanzin, K. (2018). Mitigation of temperate fruit crop problems through use of rootstock. International Journal of Chemical Studies 6(2), 880887.

Dondini, L., \& Sansavini, S. (2012). European pear (pp 363413). Fruit Breeding. Series, Handbook of Plant Breeding, Vol. 8 (Eds, Badanes, M.L., Byrne, D.H.), Springer Science+Business Media, New York, pp. 875.

FAOSTAT, (2020). Food and Agriculture Organization of the United Nations. http,//www.fao.org.tr (Erişim tarihi, 15.03.2020).

Güleryüz, M. (1991). Ülkemiz meyve fidancılığında anaç sorunu ve dünyada anaç ıslahı ile ilgili çalışmalar. Türkiye I. Fidancıllk Sempozyumu (26-28 Ekim 
1987, Tokat) Bildiriler Kitabı, T.C. Tarım ve Köyişleri Bakanlığı (Ankara), 273-284.

Hancock, J.F., \& Lobos, G.A. (2008). Pears (p 299-336). Temperate Fruit Crop Breeding, Germplasm to Genomics (Eds, Hancock, J.F.) New York, Springer. Pp. 455.

Hartmann, H.T., Kester, D.E., Davies, Jr.F.T., \& Geneve, R.L., (2011). Plant Propagation, Principles and Practices. $8^{\text {th }}$ Edition. Regents/Prentice Hall International Editions, Englewood Cliffs, New Jersey. pp. 880.

Hepaksoy, S. (2008). Meyve Fidanı Yetiştirilmesi (s. 157190). Genel Meyvecilik (1. Baskı). Nobel Yayınevi, Ankara, $492 \mathrm{~s}$

Hepaksoy, S., (2019). Meyvecilikte anaç kullanımı, armut anaçları. Türk Bilimsel Derlemeler Dergisi, 12 (2), 69-74.

Jackson, J.E. (2003). Biology of apples and pears. Cambridge, UK, Cambridge University Press. pp. 504.

Johann, G. (1983). Effect of growth regulators on branching habit of some apple cultivars in the nursery. Acta Horticulturae, 137, 87-94.

Karamürsel, Ö.F. (2008). Bazı Elma Çeşitlerinde Farklı Așı Metotları Kullanılarak Örtü Altı ve Açıkta Fidan Yetiştiriciliği. Selçuk Üniversitesi, Fen Bilimleri Enstitüsü, Yüksek Lisans Tezi, Konya, 62 s.

Lewis, W.J., \& Alexander McE, D. (2008). Grafting \& Budding. A Practical Guide for Fruit and Nut Plants and Ornamentals. Collingwood, Vic., CSIRO Publishing, Australia, pp.102.

Magyar, L., Barancsi, Z., Dickmann, A., \& Hrotko, K. (2008). Application of biostimulators in nursery, Bulletin of University of Agricultural Sciences and Veterinary Medicine Cluj-Napoca. Horticulture, 65(1), 515519.

MGM. (2019). Meteoroloji Genel Müdürlüğü. https,//www.mgm.gov.tr/tahmin/il-ve-ilceler.asp $\mathrm{x} ? \mathrm{~m}=$ SAMSUN\#/ (Erişim tarihi, 12.01.2019).

Özbek, S. (1978). Özel Meyvecilik (Kışın Yaprağını Döken Meyveler), Cukurova Üniversitesi Ziraat Fakültesi Yayınları, Adana, $128 \mathrm{~s}$.

Özçağıran, R., Ünal, A., Özeker, E., \& İsfendiyaroğlu, M. (2005). Armut (,Ilıman İklim Meyve Türleri, Yumuşak Çekirdekli Meyveler (Cilt-II), Ege Üniversitesi Ziraat Fakültesi Yayınları, İzmir, 200 s.

Özongun, Ş., Eren. İ., \& Öztürk. G. (2002). Türkiye'de meyve fidanı üretimi ve karşılaşılan başlıca sorunlar. Ziraat. Mühendisliği Dergisi, 336, 32-34.

Öztürk, B., Özcan, M., \& Öztürk, A. (2011). Farklı anac çapları ve aşılama zamanının kivi fidanı üretiminde aşı başarısı ve fidan büyümesi üzerine etkileri. Tarım Bilimleri Dergisi, 17,261-268.

Öztürk, A., \& Öztürk, B. (2014). The rootstock influences growth and development of 'Deveci' Pear. Turkish Journal of Agriculture and Natural Science, 1, 10491053.

Pektaş, M., Canll, F.A., \& Ozongun, Ş. (2009). Winter grafts as alternative methods to T-budding in pear (Pyrus communis L.) propagation. International Journal of Natural and Engineering Sciences, 3(1), 91-94.

Quinlan, J.D. (1978). The use of growth regulators for shaping young fruit trees. Acta Horticulturae, 80, 39-48.

Rahman, J., Aftab, M., Rauf, M.A., Rahman, K.U., Farooq, W.B., \& Ayub, G. (2017). Comparative study on compatibility and growth response of pear varieties on different rootstocks at nursery. Pure Applied Biology, 6 (1), 286-292.

Resmi Gazete. (1997). Meyve ve asma çeşit/anaç damızlığı fidan üretim materyali ve fidanların sertifikasyonuna ait genel esaslar tebliği. (Resmi Gazete Sayı,22868, Tebliğ No, 11, 5 Ocak 1997), Ankara.

Rom, R.C., \& Carlson, R.F. (1987). Rootstocks for Fruit Crops. John Wiley and Sons- Interscience Publication, New York, USA, pp. 497.

Saracoglu, O., \& Cebe, U. (2018). Cyclanilide Treatments Increase Lateral Branching of Apple and Pear Nursery Trees. Applied Ecology and Environmental Research, 16(4), 4575-4583.

Serttaş, S. (2019). Bazı Armut Klon Anaçları Üzerine Așılı Armut Çeşitlerinin Fidan Gelişim Performanslarının Belirlenmesi. Ondokuz Mayıs Üniversitesi, Fen Bilimleri Enstitüsü, Yüksek Lisans Tezi, Samsun, $95 \mathrm{~s}$.

Sharma, R.M., Pandey, S.N., \& Pandey, V. (2010). Breeding and Improvement. In, The Pear, Production, Postharvest Management and Protection. IBDC Publishers, India, pp. 700.

Soylu, A., Ertürk, Ü., Mert, C. \& Öztürk, Ö. (2003). MM 106 anacı üzerine aşılı elma çeşitlerinin Görükle koşullarındaki verim ve kalite özelliklerinin incelenmesi-II. Uludağ Üniversitesi Ziraat Fakültesi Dergisi, 17(2), 57-65.

Swierczynski, S., Stachowiak, A., Swierczynska, I., Golcz \& Polaszewska, M. (2014). Influence of rootstock, cultivar and ergoplant biostimulant on the growth of maiden pear trees in nursery and physiological compatibility. Acta Scientarum Polonorum Hortorum Cultus, 13(6), 3-14. 
Şahin, M. (2014). Kirazlarda Yan Dal Oluşumuna Promalin ve Malç Uygulamalarının Etkileri. Selçuk Üniversitesi Fen Bilimleri Enstitüsü, Yüksek Lisans Tezi, Konya, 72 s.

Şimsek, Y. (1987). Ağaçlandırmalarda kaliteli fidan kullanma sorunları, Ormancılık Araştırma Enstitüsü Dergisi, 33(1), 5-21.

TSE. (1996). Türk standardı, meyve fidanları, yumuşak çekirdekliler. TSE, TS 4217/Ocak 1996. Türk Standartları Enstitüsü, Ankara.
Yılmaz, M. (1994). Bahçe Bitkileri Yetiştirme Tekniği. Çukurova Üniversitesi Basımevi, Adana, 151s.

Zenginbal, E. (2016). Örtü Altı ve Arazi Koşullarında Tüplü Armut Fidanı Üretimi. Ordu Üniversitesi, Fen Bilimleri Enstitüsü, Yüksek Lisans Tezi, Ordu, 59 s.

Zenginbal, E., \& Bostan, S.Z. (2019). Bolu koşullarında açıkta ve örtü altında tüplü armut fidanı üretimi. Bahçe, 48(2), 57-64. 